\title{
Fuel enhancement of parallel hybrid electric two-wheeler motorcycle
}

\author{
V. Krithika', C. Subramani ${ }^{2}$ \\ ${ }^{1}$ Department of Mechatronics Engineering SRM Institute of Science and Technology, India \\ ${ }^{2}$ Department of Electrical and Electronics Engineering, SRM Institute of Science and Technology, India
}

\begin{tabular}{l}
\hline Article Info \\
\hline Article history: \\
Received Aug 3, 2019 \\
Revised May 29, 2020 \\
Accepted Jun 6, 2020 \\
\hline
\end{tabular}

Keywords:

Control strategy

Hybrid electric two-wheeler

MATLAB/ADVISOR

Motorcycle

Parallel hev

Power train

\begin{abstract}
In this paper, design and simulation of a parallel hybrid electric twowheeler motorcycle (PHETM) by means of continuous variable transmission (CVT) is illustrated. For simulation, the parallel hybrid electric power train model type in MATLAB/ADVISOR is customized. The internal combustion engine (ICE) be supposed to drive at elevated efficiency areas, in order to attain enhanced fuel economy and a reduced amount of emission. Simultaneously, the ICE must not activate at values of low torque areas. For that reason, get better it whilst ICE is ON, a new energy control strategy is proposed. In the new strategy, the electrical machine absorbs the extra torque of the ICE. This article proposes a PHETM system to propel the vehicle efficiently with reduced amounts of emission on comparing witha conventional vehicle. This system includes two modes of operations for achieving the better results known as motoring mode and generating mode. The switching from one mode to other is based on the vehicle speed which is sensed in real time. A drive cycle is generated by running the vehicle in normal and slightly gradient condition and finally the results are compared.
\end{abstract}

Copyright $(2020$ Institute of Advanced Engineering and Science. All rights reserved.

\section{Corresponding Author:}

C. Subramani,

Department of Electrical and Electronics Engineering,

SRM Institute of Science and Technology,

Kancheepuram, India.

Email: csmsrm@gmail.com

\section{INTRODUCTION}

Due to recent advancements in the automobile sector, the human life has become additionally at ease. Contrarily, in spite of these advancements, it has root to countless harms and indemnity to the environment counting pollutions too. The emission is quite a few chief concerns, by which the environment is more polluted [1-3]. Currently, in order to reduce pollution, a worldwide preparation is looked-for. To reduce the emissions there are few solutions, such as via electric vehicles, and hybrid electric vehicles and supplementary less polluted fuels (like fuel cells etc) [4-8].

The hybrid technology (namely hybrid energy storage systems) and hybrid electric vehicles are laid to the fore as an innovative spat. It is anticipated, that the abovementioned technology turns out to be more and more popular, due to its specifications, [9-13]. Frequently motorcycles are often used in urban areas due to traffic conditions. More pollution is emitted in urban transportation due to the incomplete combustion, as it requires a low output power. This was because of the numerous cycles of braking and movement at low tolerant speed. Conversely, passenger cars emission is a reduced amount than motorcycles [14-19]. For that reason, universally numerous researches try to crack the difficulty by means of contributing diverse 
techniques which includes the concept of hybridization [20, 21]. The minority companies created a quantity of experimental form of hybrid electric motorcycle (HEM) rather than four-wheeler vehicles. For instance, Tong et al., altered a conventional motorcycle to parallel hybrid electric motorcycle. This alteration was accomplished by affixing an electric motor passing through gearbox towards rear wheel of the vehicle [22]. Pierluigi Pisu et al premeditated about HEV efficiency and also concentrated with various topologies on the energy management strategies [23]. The conversion to a hybrid vehicle from a conventional vehicle can be easily achieved by through the road (TTR) structure. The electric machine is coupled to one axle and engine to other axle, i.e they are not connected to the rear wheel in the TTR structure of hybrid vehicle. Thus, whilst the vehicle is moving the power transmission is done by way of road and wheels from the ICE to motor/generator [24]. Matthew Young et al introduced a control strategy to renovate a 2005 model (Chevrolet Equinox) to a parallel HEV with TTR concept [25].

\section{PROPOSED SYSTEM}

In this paper, at first a design of parallel hybrid electric two-wheeler motorcycle PHETM is done with CVT and batteries (lead acid). The proposed PHETM has an electric motor connected to rear wheel using belt drive and it can run even in electric mode alone, to stay away from the ICE running at low powers. After that to simulate the model, the Parallel Hybrid Electric power train type in the MATLAB/ADVISOR is proposed. Finally, for parallel hybrid electric two-wheeler motorcycle a new control strategy is brought in to minimize the fuel consumption and emission. Based on this proposed control strategy the simulation is done. Also the hardware implementation is carried out. The output of this proposed strategy is matched up to the results of conservative motorcycle.

As seen in Figure 1, the proposed system consists of an electrical energy flow assisting the mechanical energy flow. The former is by battery powered electric motor and the latter is due to engine. Both the engine and electric motor is connected to the rear wheel of the two wheeler. The motor assists the engine. The vehicle is said to operate in electric mode if the motor alone propels the two wheeler and same way if engine is propelling the vehicle without electrical energy, then the vehicle is in engine mode. A motor controller is used to power the electric motor via battery. When the battery charge (SoC) is low, the above mentioned engine mode comes into role. Similarly, if battery is with sufficient charge and fuel tank is with less fuel, the vehicle can be operated in electric mode.

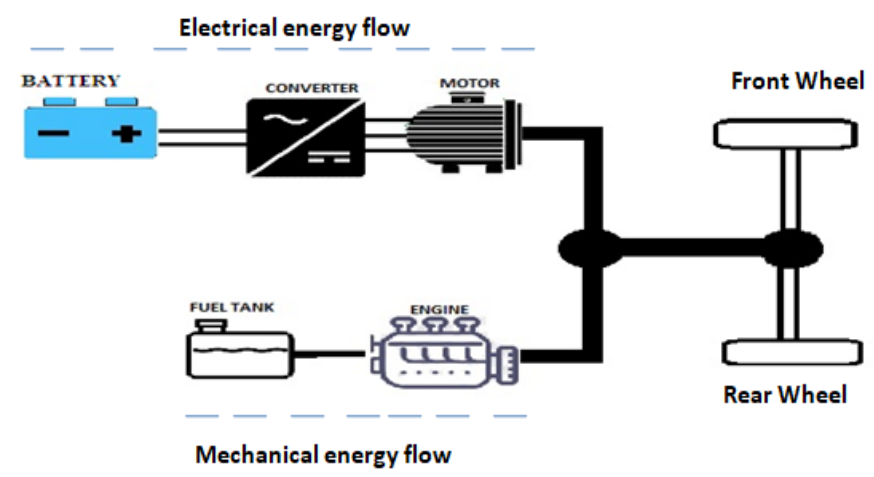

Figure 1. Block diagram of proposed system

\section{DESIGN OF A PHETM}

\subsection{Design calculation using vehicle dynamics}

The desired motorcycle should be capable enough to meet out the speed and time namely, it has to attain top speed of $50 \mathrm{~km} / \mathrm{hr}$, and the acceleration time of 10 seconds is require to reach from zero to speed of $40 \mathrm{Km} / \mathrm{hr}$. The designed motorcycle ought to be proficient to cruise in the road with grade of $10 \%$ at the speed of $20 \mathrm{Km} / \mathrm{hr}$.

The motorcycle should simultaneously retain the requisite acceleration and also capable to rise above the resistive forces. The motorcycle considered for remodelling is the TVS SCOOTY ES. The required power to triumph over the forces is able to estimate from the following equations. Total Tractive Force $(\mathrm{Ft})$ of the vehicle is given by:

$$
F_{t}=F_{r}+F_{g}+F_{d}
$$


The $F_{r}$ is the tyre rolling resistance, which is required by the vehicle to overcome the tyre and road resistances. Also the gravitational force feigning on the vehicle is represented by equation (3) and the air drag resistance is a force around vehicle body, which is formed by the flow of turbulent air. This air drag resistance can be sketched through the formula in (4).

$$
\begin{aligned}
& \text { Tire Rolling Resistance }=F_{r}=C_{r r} * m_{v e h} * g_{a c c} \\
& \text { Force Due to Gradient }=F_{g}=m_{v e h} * g_{a c c} * \sin \theta_{g} \\
& \text { Force Due to Air Drag Resistance }=F_{d}=\frac{\rho}{2} * C_{d} * A_{f} * V^{2}
\end{aligned}
$$

Here, $C_{r r}$ - Wheel Rolling Resistance Coefficient, $m_{v e h}$-Mass of the vehicle in $\mathrm{kg}, g_{a c c^{-}}$acceleration due to gravity in $\mathrm{m} / \mathrm{sec}^{2}, \sin \theta_{g}$-inclination angle in $\mathrm{rad}, \rho$ - air density in $\mathrm{kg} / \mathrm{m}^{3}, A_{f^{-}}$Frontal Area of the wheel, $V^{2}-$ Speed of the vehicle in $\mathrm{km} / \mathrm{hr}$. The specifications of the two wheeler are mentioned below, which is a 2 stroke, 60cc engine. Hence the BLDC Motor with maximum power 500W, 48V, with a rotor diameter of $24.5 \mathrm{~cm}$ and weight of $5.5 \mathrm{~kg}$ specifications is selected to match with ICE power and torque.In the Table 1 the specifications of the two wheeler considered for (Scooty Es) testing is mentioned.

Table 1. Specifications of the two wheeler (Scooty Es)

\begin{tabular}{ll}
\hline Air Drag coefficient $\left(C_{d}\right)$ & 0.88 \\
\hline Frontal Area of the wheel $\left(A_{f}\right)$ & $3.9 \mathrm{~m} 2$ \\
Mass of the vehicle $\left(m_{v e h}\right)$ & $63 \mathrm{~kg}$ \\
Wheel Rolling Resistance Coefficient $\left(C_{r r}\right)$ & 0.004 \\
Tank Capacity & $3.5 \mathrm{~L}$ \\
Wheel Base & $1165 \mathrm{~mm}$ \\
\hline
\end{tabular}

\subsection{Simulation}

The simulation was done for parallel hybrid electric vehicle with ECE drive cycle for 2 cycles. Hence the cycles for 400 seconds is considered. As shown in the Figure 2, the fuel consumption in L/100km is 6.4 litres. The total distance was considered as $2 \mathrm{~km}$. From the Figure 2, it is clear that the battery SoC drops while the emissions reduce. At some stage, in the acceleration/cruising modes, the proposed control strategy is with the intention that, only the electric motor propels the motorcycle in case if the power demand is low. But ICE propels the vehicle if in case the power required is flanked by any definite constraints. Under such circumstances, motor acts like generator and the batteries are charged (if required). The maximum power is 500 watt. The control strategy is such that the SoC of the battery becomes with reference to 0.7. Consequently, the power becomes negative, if $\mathrm{SoC}$ is greater than 0.7. It is inferred from this that electric motor aids the ICE and a fraction of necessary power is supplied. If SoC is less than 0.7, a part of the ICE power is taken up by the electric motor and also the battery is charged as mentioned before.
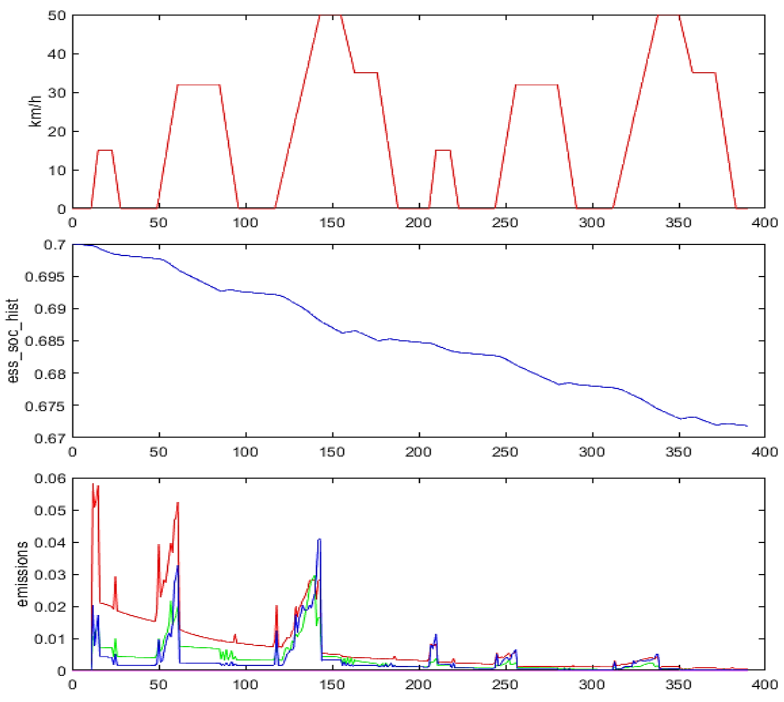

Figure 2. Simulation results 


\subsection{Hardware implementation}

\subsubsection{Mechanical integration of electric motor and ICE}

Based on the design calculations electric motor is selected. To power this motor a battery is required. In general there are two types of batteries. The primary batteries are disposable and rechargeable type comes under secondary batteries. For automotive applications, secondary batteries are preferred due to their rechargeable property. Hence, a lead acid battery of $12 \mathrm{~V}$ is used in 4 numbers. These batteries are connected in series to form a $48 \mathrm{~V}$ power supply to the electric drive circuit which is shown in Figure 3.

A bed is designed and machined to fix the motor in the vehicle as shown in Figure 4. Mild Steel is used for the purpose of Bed. A Mild steel plate of thickness ' $40 \mathrm{~mm}$ ' is cut as per dimensions of L ' $280 \mathrm{~mm}$ ' B ' $115 \mathrm{~mm}$ ' for the purpose of bed. The one end of Mild Steel plate is Arc welded with a hinge, the hinge is welded to the frame of the vehicle. Hinge is used to adjust the height of the bed at the same time limit the height adjustment, the other end of the plate is welded with bolt of ' $60 \mathrm{~mm}$ ' which is vertically welded to the frame of the vehicle. Chain drive is used to connect the motor shaft with the wheel. Chain drives links are meshed with toothed sprockets.

Chain sprockets are locked to the shafts of the driver and driven machinery. The driver sprocket is connected to motor shaft, the driven sprocket is slightly modified to function as rotating shaft as well as lock nut for the wheel. For this to happen the bore of the driven sprocket is wire cut to the shape of a lock nut and then the lock nut is fixed with the sprocket, this modified sprocket functions as driven sprocket coupled with drive shaft and at the same time locks the wheel to drive shaft shown in Figure 5. The chain drive specifications are Pitch $=13 \mathrm{~mm}$, Inside width $=4.8 \mathrm{~mm}$, Roller diameter $=8 \mathrm{~mm}$, Chain length $=45 * 13=$ $585 \mathrm{~mm}$.

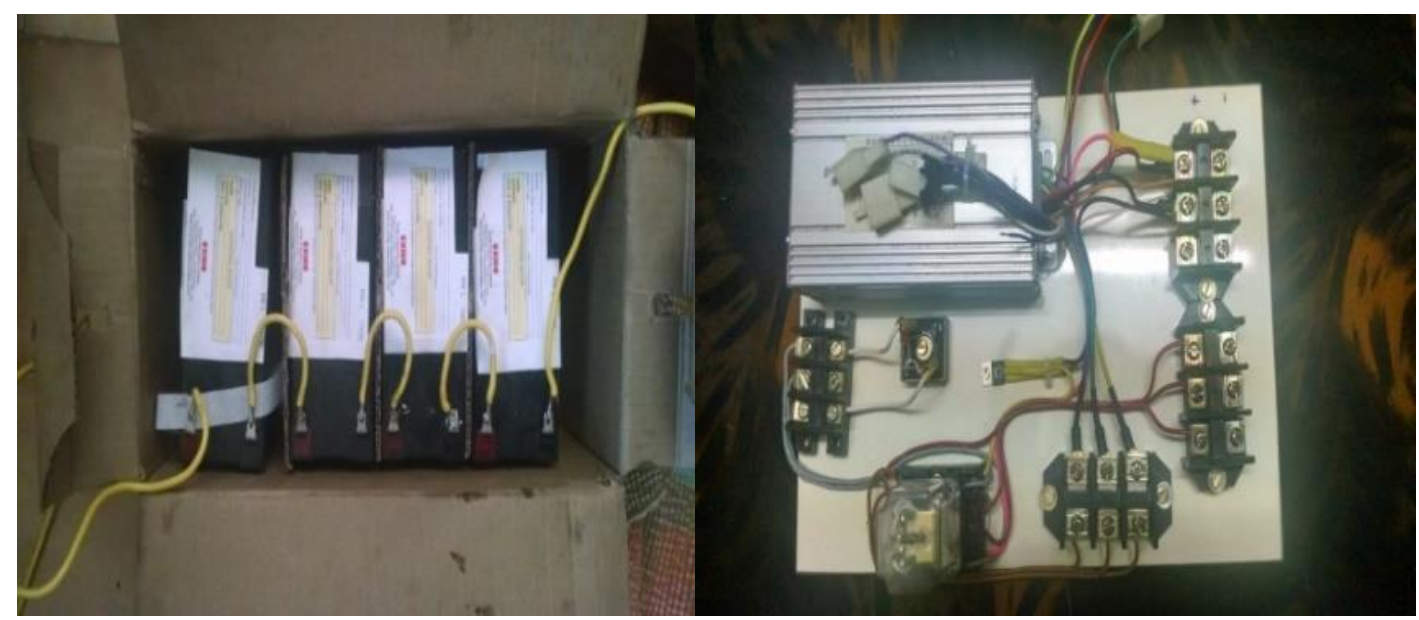

Figure 3. Batery and drive, a) batteries connected in series, b) motor controller with relay switching

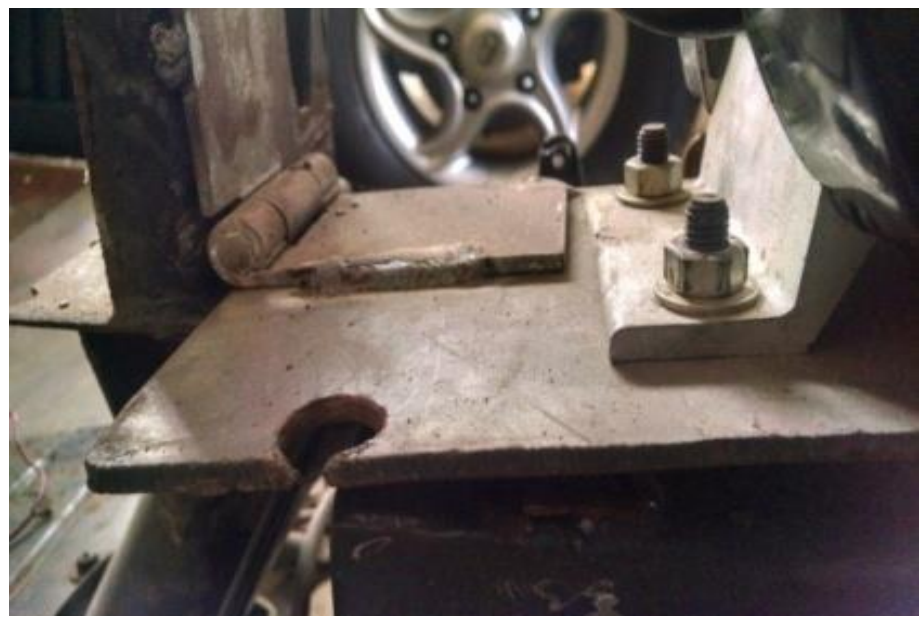

Figure 4. Mechanical bed welded for motor placement 


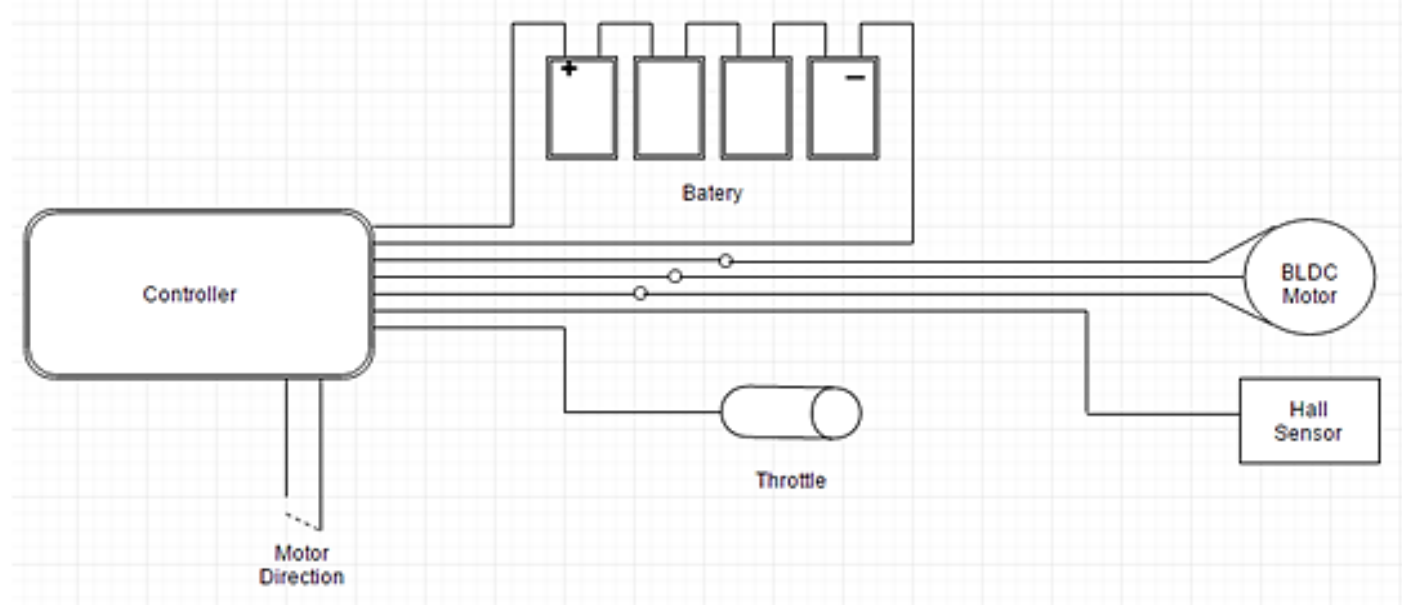

Figure 5. Electric drive circuit

As mentioned earlier, the sprockets connection with the motor and engine is shown in Figure 6. The Figures 7 and 8 represents the chain rive mechanism involved in the vehicle. The Table 2 specifies the description of the hardware parts of the entire two wheeler setup.

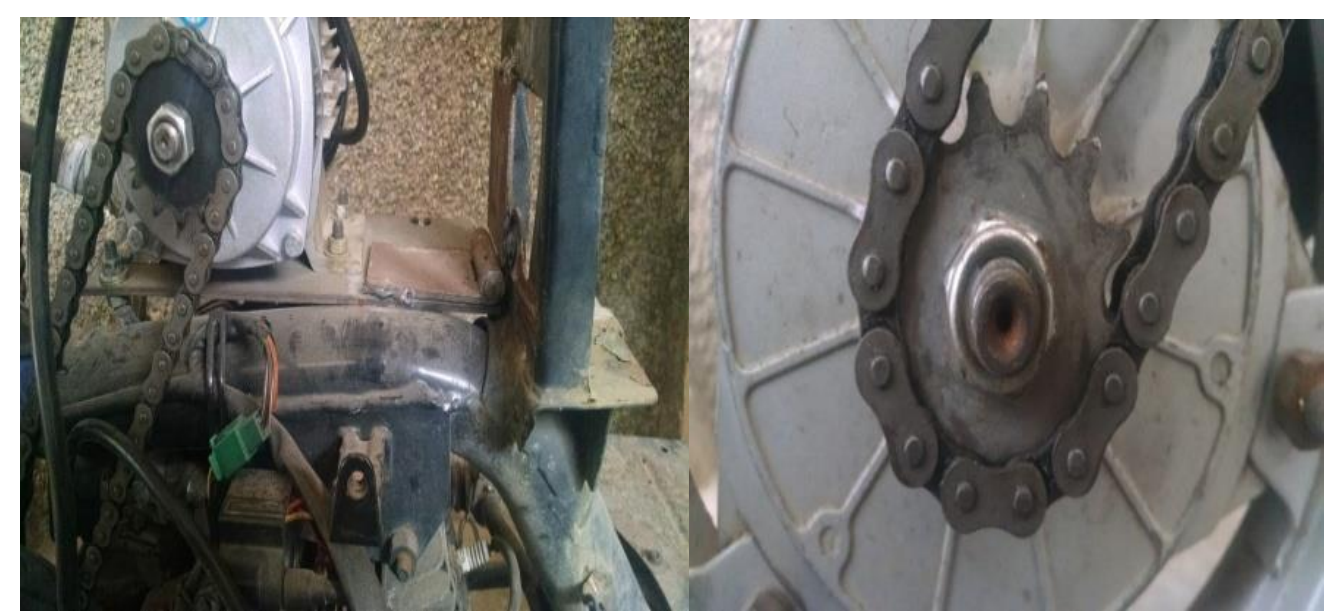

Figure 6. Arrangement of chain drive mechanism with sprockets in the motor and engine

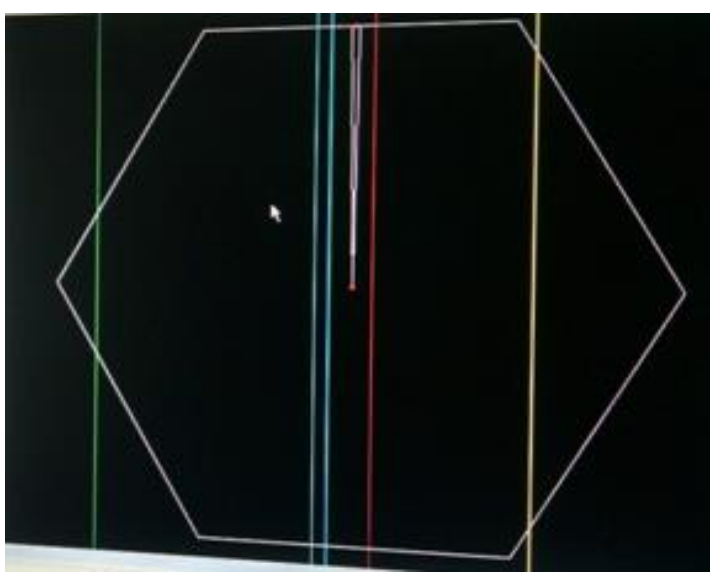

Figure 7. Chain drive mechanism design 


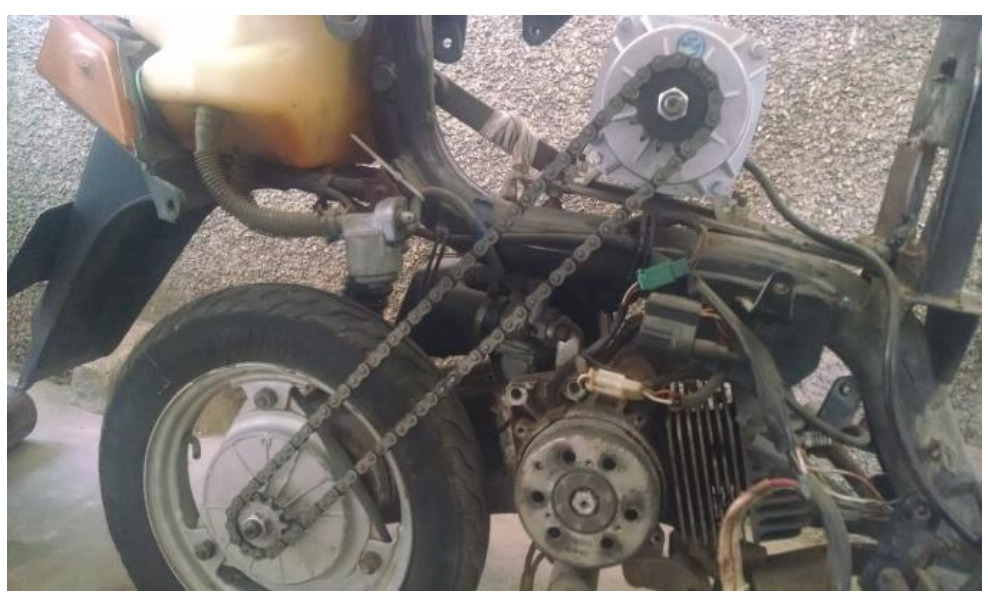

Figure 8. Chain drive transmission for motor and wheel setup and Placement of motor in motor bed and connection of wheel with motor using chain drive

Table 2. Specifications of Hardware parts of PHETM

\begin{tabular}{ccc}
\hline Name & Type & Specifications \\
\hline Electric Motor & BLDC Motor & $500 \mathrm{~W}$ \\
ICE & 2 stroke & $60 \mathrm{CC}$ \\
Relay & 11 pin and 5pin & $24 \mathrm{~V}$ and $12 \mathrm{~V}$ \\
Battery & Lead Acid & $12 \mathrm{~V}, 7 \mathrm{Ah}(4$ nos in series $)$ \\
Transmission & CVT & - \\
Microcontroller & Arduino Uno & ATmega328 \\
\hline
\end{tabular}

\subsubsection{Control strategy}

The electric motors are extremely efficient in high torque drives and for high speed drives, the internal combustion engine (ICE) are highly proficient. Hence the vehicle can be propelled using electric motors at low speeds and the ICE can be utilized to propel at high speeds. As per the control strategy, it is proposed to propel the vehicle with electric motor below the speed of $15 \mathrm{Kmph}$ and the ICE to propel above $15 \mathrm{Kmph}$ speed.

Speed of the vehicle is read with the aid of an IR Speed sensor. IR sensor is connected with fork of the vehicle. A thin metal piece is connected to wheel shaft such that when the wheel rotates this metal plate rotates and passes between the emitter and receiver of sensor. The IR sensor normally receives signal continuously thus remains high. Whenever the metal plate passes through the sensor it goes low, as a result for one rotation of wheel the plate passes through IR sensor once. The IR sensor is connected to a microcontroller which here is Arduino Uno; the arduino reads the IR output. For every low from IR sensor represents one rotation of wheel, and the arduino is programmed such that it calculates the rpm of the wheel. For the switching to happen relays are employed, these relays can be controlled by Arduino. A 11 pin $24 \mathrm{~V}$ relay and two 5 pin $12 \mathrm{~V}$ relays are used. The $11 \mathrm{Pin} 24 \mathrm{~V}$ relay is connected in between the BLDC motor controller and the BLDC Motor. The connections are such that the three poles of the motor are connected to three poles of the relay, The three output from the BLDC motor controller is connected to NC contacts of the relay, to the NO contacts a bridge rectifier is connected as shown in Figure 9.

Initially as the relay coil is not powered, the motor poles are connected to controller outputs, now the motor can propel the vehicle whereas as soon as relay coil is powered, the poles are connected to the bridge rectifier i.e, the motor poles are not connected to controller output, hence there is no power flow from battery to motor, hence the motor cannot propel the vehicle, but when the motor shaft is rotated by IC engine a $\mathrm{Ac}$ is generated which is rectified by bridge rectifier and fed to batteries, thus acting as generator. Thus when this $24 \mathrm{~V}$ relay coil is not powered, the motor propels the vehicle. When $24 \mathrm{~V}$ relay coil is energized, the motor acts as generator; i.e the ICE propels the vehicle. For the ICE to switch ON and OFF the two 5 pin $12 \mathrm{~V}$ relays are used. The relays are connected such that, the NO contact of Relay 1 is connected instead of self start switch of the self start motor.

Now for the engine to switch $\mathrm{ON}$, the relay 1 coil is powered for few seconds, which closes the circuit between battery and self start motor, thus self start motor is powered as long as relay is powered, self start motor assists to switch on the engine. The NO contact of Relay 2 is connected in between the spark plug and ignition coil. The Arduino is coded such as to read the speed of the vehicle as well as switch 
the conditions of the vehicle based on the speed of the vehicle. Relay 2 works such that as long as relay 2 coil is powered the spark plug can begin combustion in every stroke of engine and when relay 2 coil is de energized the spark plug cannot produce sparks thus engine is switched off.

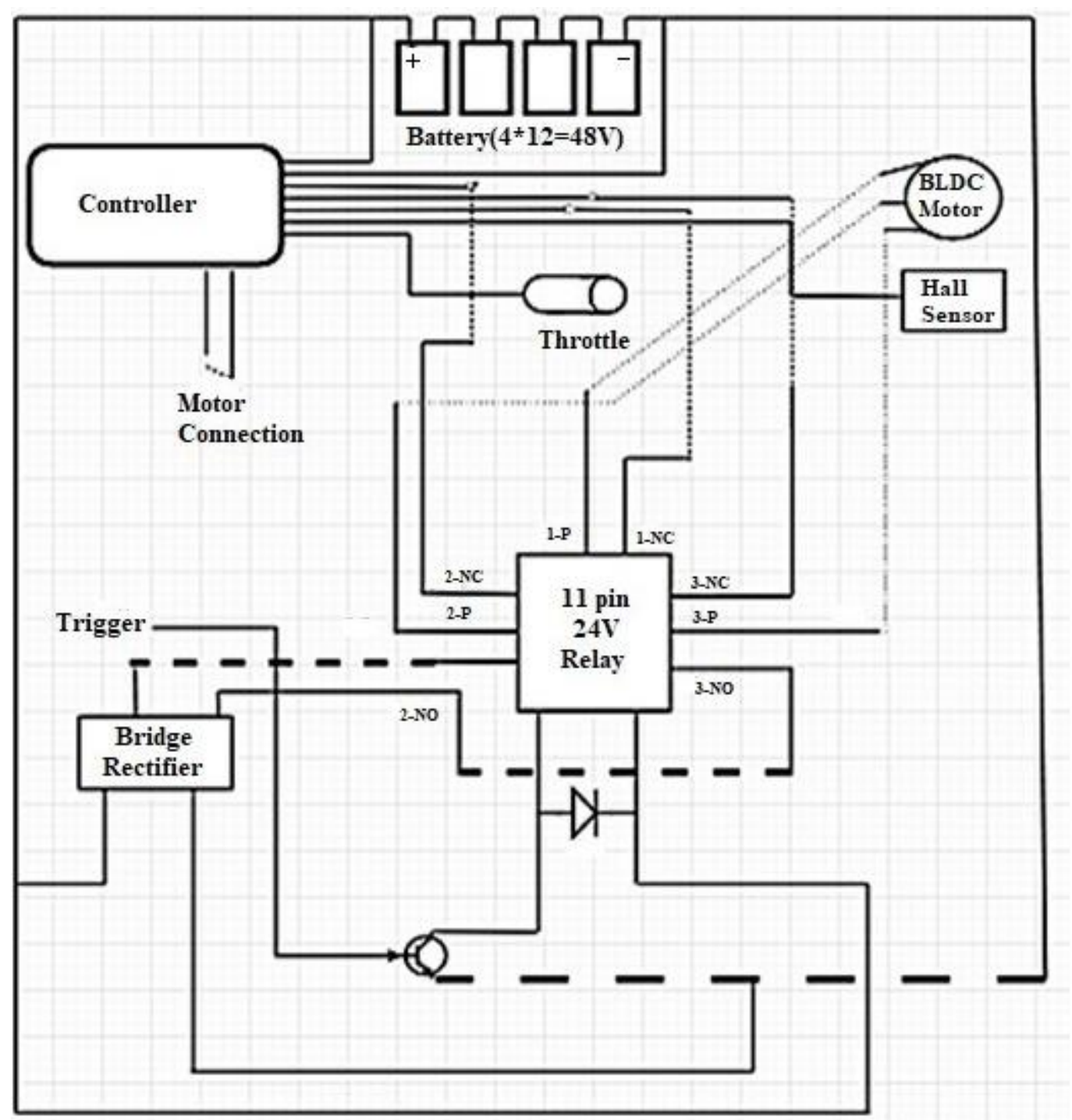

Figure 9. Complete PHETM control circuit

\section{RESULTS AND DISCUSSION}

The hybrid power model was tested with standard test driving cycles $(800 \mathrm{~s}$ altogether $)$ in the platform. The load is fixed with one person weighing $60 \mathrm{~kg}$ and also at two different test cases for comparison, one with electric charger i.e battery with motor in platform type road and the other one, slightly slope terrain conditions, is conducted correspondingly. The results of both the road tests are presented below.

The results as shown in Figure 10 infer that the battery charge is decresed drastically in slightly gradient contions compared to a plain road. Also the drive cycle (speed vs time) pattern which is a real time drive cycle observed is varying much as shown in Figure 11. The drive cycle plays a vital role in efficiency enhancement of a vehile. Henceforth, the drive cycle analysis for each road type should be considered for future study to enhance the overall efficiency of the vehicle. Although in Figure 12, there is not much difference seen, for a covering a particular distance in a specified time. It can be seen that there is a delay or in other words more time is consumed to cover the same distance when the vehicle is travelling in a sloppy region compared to a plain terrain. 


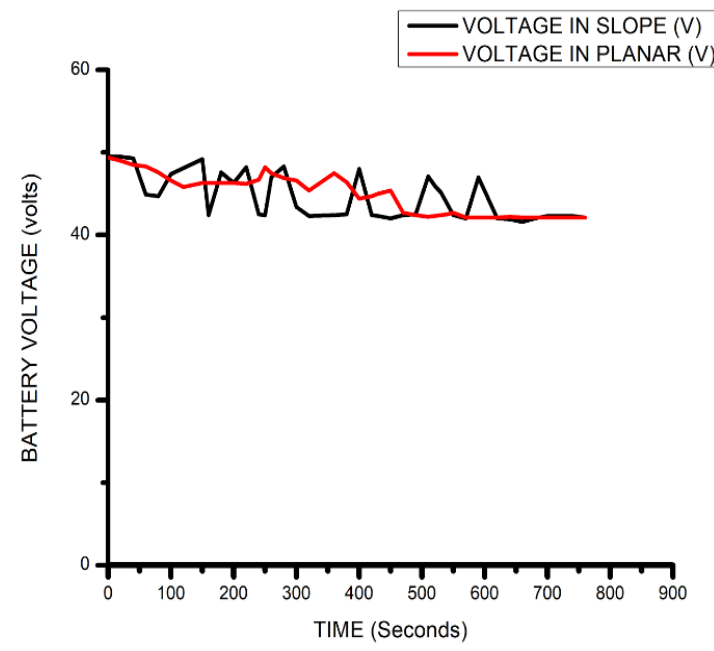

Figure 10. Comparison of battery voltages in the PHETM for two different road types (slope and planar)

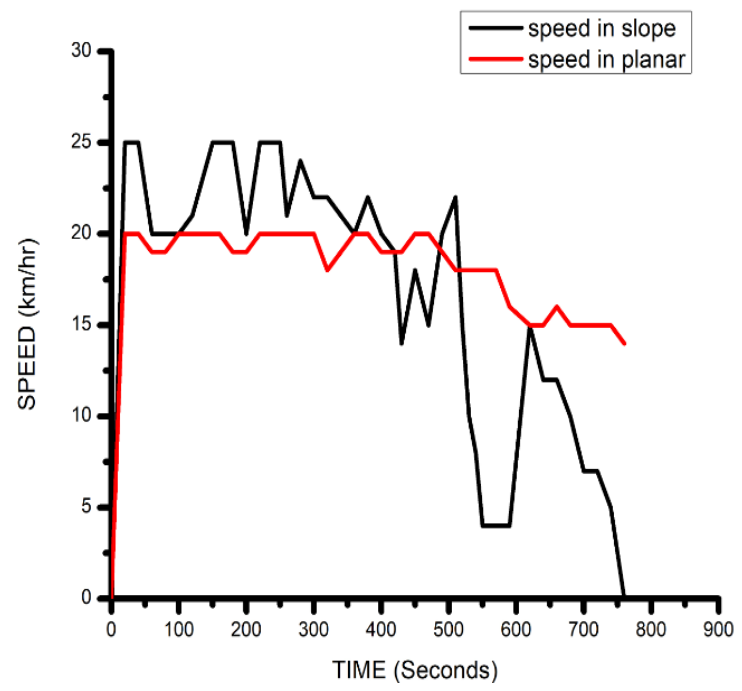

Figure 11. Comparison of drive cycle of PHETM results in two different road types (slope and planar)

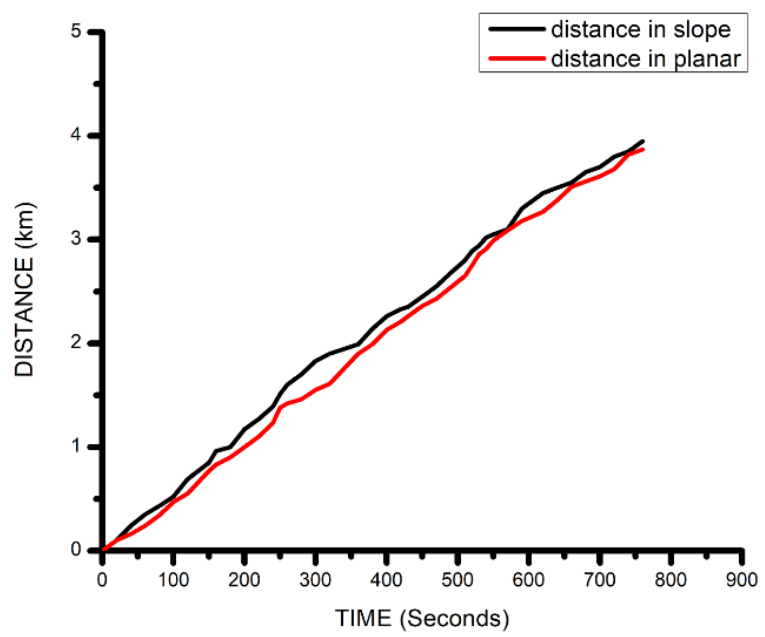

Figure 12. Comparison of PHETM results in two different road types (slope and planar) for a particular distance 


\section{CONCLUSION}

In this paper, the work to design and simulation (with the MATLAB/ADVISOR) of a parallel hybrid electric two-wheeler motorcycle (PHETM) with CVT is achieved. A hardware model is also developed and platform and road tests were conducted. In order to attain superior fuel economy and a reduced amount of emission, ICE be supposed to not drive at petite efficiency regions. The efficiency becomes dreadful when engine torque is low. For that reason, the control strategy is improvised, to facilitate as soon as the engine is $\mathrm{ON}$, it produces a least amount torque. By that time period the electric motor absorbs extra torque which is saved in batteries (lead acid) connected to the motor.

\section{REFERENCES}

[1] Geetha A and Subramani C., "A comprehensive review on energy management strategies of hybrid energy storage system for electric vehicles," Int J Energy Res, vol. 41, pp. 1817-1835, 2017.

[2] M. Ehsani, E. Gao, S. E.Gay, and A. Emdadi, "Modern Electric, Hybrid Electric, and Fuel Cell Vehicles," $C R C$ press, pp. 1-4, 2005.

[3] M. Shafiepour, and H. Kamalan, "Air Quality Deterioration in Tehran due to Motorcycles," Iran Environment Health Sci., Eng., vol. 2, Nno. 3, pp. 145-152, 2005.

[4] Krithika V and Subramani C., "A comprehensive review on choice of hybrid vehicles and power converters, control strategies for hybrid electric vehicles," Int J Energy Res, vol. 42, pp. 1789-1812, 2018.

[5] A. N. Bleijenberg and J. M. W. Dings, "European transport: emission trends and policy responses," Center for Energy Conservation and Environmental Technology, 2009.

[6] Krithika V, Subramaniam C, Sridharan R and Geetha A., "Multi Bus DC-DC Converter in Electric Hybrid Vehicles," Journal of Physics: Conference Series, 2018.

[7] G. Panzani, M. Corno, and S. M. Savaresi, "On adaptive electronic throttle control for sport motorcycle," Control Engineering Practice, vol. 21, pp. 42-53, 2013.

[8] Juan-Gerardo Parada-Salado, Luis-Fernando Gaona-Cardenas, et.al., "Harvesting in electric vehicles: Combining multiple power tracking and fuel-cells," International Journal of Electrical and Computer Engineering (IJECE), vol. 10 , no. 5, pp. 5058-5073, 2020.

[9] A. Geetha, C. Subramani, "A significant energy management control strategy for a hybrid source EV'," International Journal of Electrical and Computer Engineering (IJECE), vol. 9, no. 6, pp. 4580-4585, 2019.

[10] Gong Q, Midlam-Mohler S, Marano V, Rizzoni G, "An iterative Markov chain approach for generating vehicle driving cycles," SAE International Journal of Engines, vol. 4, pp. 1035-1045, 2011.

[11] Kim N, Rousseau A, and Rask E, "Autonomie model validation with test data for 2010 Toyota Prius," Fuel, vol. 48, 2012.

[12] M. Kavitha, V. Elanangai, S. Jayaprakash, and V. Balasubramanian, "Development of Regenerative Braking Concept for Electric Vehicle Enhanced with Bidirectional Converter," International Journal of Power Electronics and Drive Systems (IJPEDS), vol. 9, no. 4, pp. 1584-1590, 2018.

[13] J. S. Norbakyah, and A. R. Salisa," Optimization of the fuel economy and emissions for plug in hybrid electric recreational boat energy management strategy using genetic algorithm," International Journal of Power Electronics and Drive Systems (IJPEDS), vol. 10, no. 2, pp. 792-800, 2019.

[14] J. I. N. Anida, A. R. Salisa," Driving cycle development for Kuala Terengganu city using k-means method," International Journal of Electrical and Computer Engineering (IJECE), vol. 9, no. 3, pp. 1780-1787, 2019.

[15] Hsu Yuan-Yong, Lu Shao-Yuan., "Design and implementation of a hybrid electric motorcycle management system," Applied Energy, vol. 87, no. 11, pp. 3546-3551, 2010.

[16] Yimin Gao and Mehrdad Ehsani, and John M. Miller, "Hybrid Electric Vehicle: Overview and State of the Art," IEEE ISIE, 2005.

[17] Sharada Prasad. N, "Design and Development of Hybrid Electric Two-Wheeler with Solar Charging Methodology," International Journal of Scientific Engineering Research, vol. 5, no. 11, 2014.

[18] Sagar Tatipamula, "Study of a Parallel Electric Hybrid Three-Wheeled Motor Taxi," IJCA Proceedings on International conference on Green Computing and Technology, pp. 38-41, 2013.

[19] Tong, Chia-Chang and Jwo, Wu-Shun., "An assist-mode hybrid electric motorcycle," Journal of Power Sources, vol. 174, pp. 61-68, 2007.

[20] J. S. Norbakyah, and A. R. Salisa," A Study on PHERB Powertrain Modeling and Analysis," International Journal of Electrical and Computer Engineering (IJECE), vol. 8, no. 3, pp. 1822-1829, 2018.

[21] Vanangamudi S, Prabhakar S,Thamotharan C,Anbazhagan R, "Hybrid two wheeler," Middle-East Journal of Scientific Research, vol. 20, pp. 726-727, 2014.

[22] Chia-Chang Tong, and Wu-Shun Jwo, “An assist-mode hybrid electric motorcycle," Journal of Power Sources, vol. 174, pp. 61-68, 2007.

[23] P.Pisu, K. Koprubasi and G. Rizzoni, "Energy Management and Drivability Control Problems for Hybrid Electric Vehicles," 44th IEEE Conference on Decision and Control, and the European Control Conference, 2005.

[24] Josef B. Kejha, Sagar N. Venkateswaran, "Low cost inversion of any internal combustion vehicle into hybrid electric vehicle," US patent, 2008.

[25] Matthew Young, et al,"The Design and Development of a Through-the-Road Parallel Diesel Electric Hybrid," IEEE Vehicle Power and Propulsion Conference, 2007. 